\title{
MONITORAMENTO DA ÁGUA EM BACIA HIDROGRÁFICA COM DIFERENTES USOS DO SOLO NO MUNICÍPIO DE RIO VERDE (GO)
}

\author{
Gilmar Oliveira Santos* \\ Renystton de Lima Ribeiro** \\ Túlio Pereira Parreira*** \\ Daniela Ferreira da Silva**** \\ Kalyne Afonso Silva***** \\ Camilla Frazão Azeredo******
}

RESUMO: A degradação dos ecossistemas aquáticos, resultante da má gestão do uso do solo e das atividades antropogênicas, constitui uma das grandes preocupações ecológicas dos últimos anos por reduzir a disponibilidade e qualidade dos recursos hídricos. Portanto, o trabalho teve como objetivo caracterizar a variabilidade temporal e espacial da qualidade e disponibilidade hídrica e a relação com o uso do solo na bacia hidrográfica do córrego do Sapo, município de Rio Verde, Goiás, Brasil. Para constatar a influência utilizou-se imagem de satélite ESRI; Google Earth. O monitoramento qualitativo (químico, físico e microbiológico) e quantitativo da água foi realizado bi-mensal no ano de 2016. A bacia se caracterizou com maior parte agrícola $(57,3 \%)$, portanto, os impactos de restrição de uso da água são advindos em maior parte da área urbana que corresponde a $20 \%$ da área de influência. Houve bons índices de qualidade da água e potencial de irrigar até 899 hectares, portanto, a presença de coliformes restringe o uso da água em culturas de consumo direto. Devido à presença de ferro na água, a instalação de sistemas de irrigação deve ser acompanhada de sistemas de filtragem para retenção das partículas e, consequentemente, melhor aproveitamento do equipamento. A disponibilidade hídrica passa por oscilações devido à falta de áreas de preservação permanente. Há necessidade

\footnotetext{
Doutor em Agronomia, docente permanente da Faculdade de Engenharia Ambiental e Agronomia da Universidade de Rio Verde - UniRV, Brasil. Email: gilmar@unirv.edu.br

** Mestre em Agronomia, docente permanente da Faculdade de Engenharia Ambiental da Universidade de Rio Verde - UniRV, Brasil.

${ }^{* * *}$ Engenheiro Ambiental pela Universidade de Rio Verde - UniRV, Brasil.

${ }^{* * * * *}$ Engenheira Ambiental pela Universidade de Rio Verde - UniRV, Brasil

${ }_{* * * * * *}^{*}$ Graduanda em Engenheira Ambiental pela Universidade de Rio Verde - UniRV, Brasil.

${ }^{* * * * * * *}$ Engenheira Ambiental pela Universidade de Rio Verde - UniRV, Brasil
} 
de implementar medidas de planejamento estratégico de gestão dos recursos hídricos na bacia hidrográfica do córrego do Sapo para recuperação e melhoria da qualidade e disponibilidade hídrica.

PALAVRAS-CHAVE: Geoprocessamento; Irrigação; Qualidade da água; Vazão.

\section{MONITORING WATER IN A HYDROGRAPHIC BASIN WITH DIFFE- RENT SOIL USES, IN RIO VERDE, BRAZIL}

ABSTRACT: The degradation of aquatic ecosystems caused by the bad administration of soil use and by human activity, is one of the most important ecological concerns due to a reduction of availability and quality of water resources. Current study characterizes the temporal and spatial variability of water quality and availability, coupled to soil use in the hydrographic basin of the Corrego do Sapo, municipality of Rio Verde GO Brazil. ESRI satellite image, Google Earth, was used to pinpoint the influence. Qualitative (chemical, physical and microbiological) and quantitative monitoring of water was done twice a month during 2016. The basin is characterized by $57.3 \%$ agriculture and impacts on the restriction in water use mainly derive from the urban area which corresponds to $20 \%$ of the influence area. Although there were good indexes of water quality and potential to irrigate up to 899 hectares, coliforms restrict water use in direct consumption cultures. Due to iron in the water, the installation of irrigation systems should be followed by filter systems for particle retention and, consequently, for the better use of the equipment. Hydric availability oscillates because of the absence of permanent preservation areas. Strategic and administrative planning of water resources in the hydrographic basin of the Córrego do Sapo should be implemented to recover and improve water quality and availability.

KEY WORDS: Geoprocessing; Irrigation; water quality; discharge.

\section{INTRODUÇÃO}

No município de Rio Verde, muitos dos ribeirinhos são dependentes de um ou mais mananciais para assegurar sua sobrevivência, porém, a maioria desses usuários não possui orientação sobre a importância das características físico-químicas e microbiológicas para os diversos usos da água e de seus respectivos riscos a saúde e ao meio ambiente (DALASTRA et al., 2014), além de poder comprometer a economia 
local através da agricultura irrigada.

As degradações dos mananciais estão relacionadas às degradações oriundas das áreas rurais e urbanas, sendo aceleradas pela ação antrópica. As áreas rurais contribuem através da ausência de manejo adequado do solo, que resulta consequentemente na erosão hídrica, propiciando a redução de oferta e da qualidade hídrica e drástica alteração da cobertura florestal (PEREIRA et al., 2016).

$\mathrm{Na}$ área urbana, o acelerado crescimento propicia a degradação dos ecossistemas aquáticos devido a supressão da vegetação, uso inadequado do solo (PRADO et al., 2017) e lançamentos clandestinos de efluentes nos mananciais, resultando na diminuição da disponibilidade e qualidade dos recursos hídricos conforme já observado por Menezes et al. (2016), Dalastra et al. (2014), Oliveira, Nogueira e Sartori (2014) e Vanzela, Hernandez e Franco (2010), em outros municípios.

O município de Rio Verde possui 57,1\% do esgoto coletado e tratado (RIO VERDE, 2016). Para Sherer et al. (2016) em regiões onde não há rede de coleta de esgoto, a contaminação das águas dos mananciais por efluentes domésticos pode reduzir o índice de qualidade da água (IQA), causar impactos significativos sobre a saúde humana e inibir o uso em culturas de consumo direto.

O Brasil possui grande potencial hídrico, porém com deficiência em termos de monitoramento qualitativo, quantitativo e conhecimento das influências do uso do solo (SANTOS; HERNANDEZ, 2013).

Os recursos hídricos sempre foram e serão os recursos naturais essenciais para o desenvolvimento de uma região, portanto, conhecer a dinâmica da qualidade da água por influência do uso e ocupação do solo e as estações do ano é de fundamental relevância para a engenharia de recursos hídricos (TERNUS et al., 2011).

O comportamento da qualidade da água reflete as condições ambientais da bacia hidrográfica (BERTOSSI et al., 2013; SOUZA; GASTALDINI, 2014), associado ao uso e ocupação do solo, possibilita detectar alterações provenientes das atividades humanas. Para Menezes et al. (2016) e Carvalho et al. (2015) a influência das atividades humanas na bacia hidrográfica é claramente refletida nos parâmetros físico-químicos e biológicos na água.

Segundo Vanzela, Hernandez e Franco (2010) o uso e ocupação dos solos exercem influência marcante no escoamento superficial e aporte de sedimentos 
no leito dos mananciais, podendo alterar a qualidade e a disponibilidade hídrica. De acordo com Pereira et al. (2016) o mapeamento do uso e ocupação do solo propicia na tomada de decisão para a manutenção das bacias hidrográficas, para o planejamento territorial, e o monitoramento do uso sustentável e legal dos recursos naturais.

O monitoramento do córrego do Sapo é de fundamental importância para o município de Rio Verde, pois suas águas são potencialmente utilizadas pela população, dessedentação de animais e na irrigação de pequenas áreas como as hortas que circundam sua área de influência, além de ser o manancial de lançamento de efluente de esgoto tratado.

Portanto, o trabalho teve como objetivo caracterizar a variabilidade temporal e espacial da qualidade e disponibilidade hídrica e a relação com o uso do solo na bacia hidrográfica do córrego do Sapo, município de Rio Verde, Goiás, Brasil.

\section{MATERIAL E MÉTODOS}

\subsection{CARACTERIZAÇÃO DA ÁREA DE ESTUDO}

O município de Rio Verde está localizado na região Sudoeste do Estado de Goiás na coordenada geográfica $17^{\circ} 47^{\prime} 53$ ”S e $51^{\circ} 55^{\prime} 53$ ”'O, com área territorial de $8.379,661 \mathrm{~km}^{2}, 176.424$ habitantes (BRASIL, 2010) e a densidade demográfica de 21 habitantes por $\mathrm{km}^{2}$.

Este trabalho foi conduzido na bacia hidrográfica do córrego do Sapo, que compreende a bacia hidrográfica do Rio São Tomás, localizada no município de Rio Verde, região Sudoeste do Estado de Goiás, localizada na coordenada geográfica $17^{\circ} 47^{\prime} 53^{\prime}$ 'S e $51^{\circ} 55^{\prime} 33^{\prime}$ 'O, com altitude média de $748 \mathrm{~m}$ acima do nível do mar, abrangendo uma área total de $8.415,4 \mathrm{~km}^{2}$. Esta bacia tem como leito principal o córrego do Sapo, com cerca de 48,8 km de extensão, sendo sua nascente situada próximo ao município de Rio Verde, em área rural, e caminha no sentido Sudoeste, até sua foz na confluência com o Rio São Tomás.

O clima da região é caracterizado como tropical úmido, com duas estações 
bem definidas, verão chuvoso, de outubro a abril, e inverno seco, de maio a setembro. No período chuvoso apresenta uma precipitação média mensal acima de 200 mm e temperatura média de $24^{\circ} \mathrm{C}$, já no período seco essa precipitação mensal é menor que $50 \mathrm{~mm}$, com temperatura média de $22^{\circ} \mathrm{C}$ (INMET, 2015).

A topografia é levemente ondulada com predominância de solo classificado como Latossolos Vermelhos e Latossolos Vermelho-Amarelos, com características de solo tipicamente profundo, bem drenado, bastante poroso, com avançado estágio de intemperismo e processo intensivo de lixiviação (ACQUA et al., 2013).

\subsection{USO E OCUPAÇÃO DO SOLO}

O uso e ocupação do solo foram definidos a partir da imagem Landsat, sensor ETM, resolução de 15-30 m, do ano de 2016, para classificação das feições. Utilizou-se o banco de imagens do software Arc GIS ${ }^{\circledR}$ versão 10.1 (basemap layers; licença: 448431) para marcação da hidrografia e a delimitação das áreas das bacias.

A metodologia adotada para a classificação foi a supervisionada por meio do algoritmo de máxima verossimilhança, em oito classes de uso e cobertura da bacia hidrográfica (cultivos, urbanização, vegetação arbórea, vegetação rasteira, represamento natural, solo exposto, vias de acesso e infraestrutura).

A bacia hidrográfica do córrego do Sapo foi fragmentada em três sub-bacias delimitadas por meio de seus divisores topográficos, considerando os pontos de coleta de água preestabelecidos.

\subsection{AMOSTRAGEM}

Foram realizadas seis coletas de água em cada um dos três pontos selecionados, dos quais dois eram em área rural (montante e jusante da área urbana) e um em área urbana. Os pontos ficaram distantes da nascente (sub-bacia 1) 7,6 km e 11,4 $\mathrm{km}$, respectivamente, em linha reta.

As coletas foram realizadas no ano de 2016, compreendendo as duas estações do ano, a seca (coletas em maio, julho e setembro) e a chuvosa (coletas em janeiro, março e novembro). 
A amostragem da água nos diferentes pontos foi do tipo manual e próximo à superfície, em razão da pouca profundidade dos mananciais conforme realizado por Menezes et al. (2016). Os demais procedimentos são apresentados por Santos e Hernandez (2013).

\subsection{QUALIDADE HÍDRICA}

As análises físicas, químicas e biológicas foram realizadas no Microlab - Laboratório de Análises Microbiológicas e Ambientais, Goiânia, Goiás. Os elementos e a metodologia utilizada nas análises foram elemento e método: $\mathrm{pH}$, eletrometria; temperatura, termometria; turbidez, nefelometria; condutividade elétrica, potenciometria; sólidos dissolvidos e totais, gravimetria; ferro, colometria; oxigênio dissolvido, cálcio e magnésio, titulação; demanda bioquímica de oxigênio, incubação a $20{ }^{\circ} \mathrm{C}$; demanda química de oxigênio, fósforo total, nitrato, nitrito e amônia, espectrometria; potássio total, absorção atômica; coliformes termotolerantes e totais, substrato enzimática.

Para o cálculo do Índice de Qualidade de Água (IQA), empregaram-se nove parâmetros, tal como proposto pelo IGAM (2005). Para cada parâmetro da Equação 1, que define o IQA, foi utilizado o peso de sua importância na determinação do IQA. Os pesos aplicados para cada variável avaliada foram: para OD (\% saturação), 0,17; coliformes termotolerantes (NMP $\left.100 \mathrm{~mL}^{-1}\right), 0,15$; $\mathrm{pH}, 0,12$; DBO $\left(\mathrm{mg} \mathrm{L}^{-1}\right), 0,10$; $\mathrm{NO}_{3}^{-}\left(\mathrm{mg} \mathrm{L}^{-1}\right), 0,10 ; \mathrm{PO}_{4}^{-3}\left(\mathrm{mg} \mathrm{L}^{-1}\right), 0,10$; turbidez (UNT), 0,08; ST (mg L $\left.{ }^{-1}\right), 0,08$; e T $\left({ }^{\circ} \mathrm{C}\right), 0,10$.

$$
\mathrm{IQA}=\prod_{\mathrm{i}=1}^{\mathrm{n}} \mathrm{q}_{\mathrm{i}}^{\mathrm{w}}
$$

em que:

IQA = Índice de Qualidade de Água (0-100);

wi = peso relativo do i-ésimo parâmetro;

qi = valor do subíndice relativo ao i-ésimo parâmetro;

$\mathrm{n}=$ número de variáveis. 
Foram utilizados os seguintes indicadores de qualidade da água, segundo a classificação: excelente $(90<$ IQA $<100)$, bom $(70<$ IQA $<90)$, médio $(50<$ IQA $<70)$, ruim $(25<$ IQA $<50)$ e muito ruim $(25<$ IQA $<0)$.

Utilizou-se o modelo proposto por Lamparelli (2004) para determinar o Índice de Estado Trófico (IET) do córrego do Sapo (Equação 2).

IET $=10 \times\left[6-\left(\frac{0,42-0,36 \times \ln (\mathrm{P})}{\ln 2}\right)\right]-20$

em que:

IET = Índice de estado trófico;

$\mathrm{P}=$ Fósforo total $\left(\mathrm{mg} \mathrm{L}^{-1}\right)$;

$\ln =$ Logaritmo natural.

Para a interpretação do estado trófico dos corpos aquáticos, utilizaram-se os seguintes limites: ultraoligotrófico (IET $\leq 47)$, oligotrófico $(47<$ IET $\leq 52)$, mesotrófico $(52<$ IET $\leq 59)$, eutrófico $(59<$ IET $\leq 63)$, supereutrófico $(63<$ IET $\leq 67)$ e hipereutrófico (IET $>67$ ).

\subsection{DISPONIBILIDADE HÍDRICA}

A área da seção molhada (S) foi determinada através do software AutoCAD, onde são colocados os valores de altura da seção e sua respectiva largura (SANTOS; HERNANDEZ, 2013) multiplicado pela velocidade de escoamento (Equação 3).

$$
Q=\frac{\Delta L}{\Delta t} \quad S
$$

em que:

$\mathrm{Q}=$ Vazão do manancial $\left(\mathrm{m}^{3} \mathrm{~s}^{-1}\right)$;

$\Delta \mathrm{L}=$ Distância percorrida pelo flutuador $(\mathrm{m})$;

$\Delta \mathrm{t}=$ Tempo gasto pelo flutuador $(\mathrm{s})$;

$\mathrm{S}=$ Área da seção molhada $\left(\mathrm{m}^{2}\right)$. 


\subsubsection{Análise estatística exploratória}

Para interpretação dos dados qualitativos dos recursos hídricos foi realizada a análise de agrupamento por método hierárquico através do software STATISTI$\mathrm{CA}^{\circledR}$, versão 7.0 (STATSOFT, 2004). O biplot foi realizado por componentes principais ortogonais apresentando a distribuição dos acessos e as direções dos feixes de variáveis.

\section{RESULTADO E DISCUSSÃO}

As sub-bacias 1, 2 e 3 do córrego do Sapo possuem 0,3, 38,4 e 135,1 km², respectivamente. As sub-bacias possuem baixa densidade de drenagem e declividade e consequentemente longo tempo de concentração, sendo propício para a retenção de água na bacia (Tabela 2).

As sub-bacias 2 e 3 apresentaram tendência mediana a grandes enchentes em condições normais de precipitação, porém, quando ocorrer com grande intensidade, as sub-bacias estarão sujeitas a grandes enchentes. A continuidade da expansão urbana dentro da área do córrego do Sapo, conforme já prevista no Plano Diretor Municipal, poderá comprometer a área urbana e rural com o aumento das enchentes.

Tabela 1. Caracterização fisiográfica das sub-bacias do córrego do Sapo, município de Rio Verde, Goiás

(Continua)

\begin{tabular}{lcccc}
\hline \multirow{2}{*}{ Características } & \multirow{2}{*}{ Unidade de medida } & \multicolumn{3}{c}{ Sub-bacias } \\
\cline { 3 - 5 } & & $\mathbf{1}$ & $\mathbf{2}$ & $\mathbf{3}$ \\
\hline Área de drenagem (A) & $\mathrm{km}^{2}$ & 0,3 & 38,4 & 137,8 \\
Perímetro (P) & $\mathrm{km}$ & 3,4 & 24,1 & 48,8 \\
Comprimento do leito principal (Lp) & $\mathrm{km}$ & 0,8 & 9,1 & 22,1 \\
Coeficiente de compacidade (kc) & - & 1,68 & 1,09 & 1,18 \\
Fator de forma (kf) & - & 0,80 & 0,67 & 0,32 \\
Índice de conformação (Ic) & - & 0,16 & 0,47 & 0,38 \\
\hline
\end{tabular}


Conclusão

\begin{tabular}{lcccc}
\hline \multirow{2}{*}{ Características } & Unidade de medida & \multicolumn{3}{c}{ Sub-bacias } \\
\cline { 3 - 5 } & & $\mathbf{1}$ & $\mathbf{2}$ & $\mathbf{3}$ \\
\hline Índice de circularidade (Icc) & - & 0,35 & 0,83 & 0,73 \\
Ordem do córrego (O) & $\circ$ & 1 & 4 & 4 \\
Densidade de drenagem (Dd) & $\mathrm{km} \mathrm{km}^{-2}$ & 2,48 & 0,79 & 0,51 \\
Densidade da rede de drenagem (Dr) & canais km ${ }^{-2}$ & 3,33 & 0,86 & 0,70 \\
Declividade equivalente (S) & $\%$ & 4,8 & 2,2 & 1,1 \\
Tempo de concentração (Tc) & min & 54,1 & 363 & 736 \\
\hline
\end{tabular}

Foram identificadas seis classes de uso do solo, sendo o uso de maior incidência na sub-bacia 1 a vegetação rasteira (41,5\%) e solo exposto $(23,2 \%)$ e nas sub-bacias 2 e 3 foram cultivos e áreas urbanizadas, correspondendo a 53,5\% e 31\%, na sub-bacia 2, e 57,3\% e 20\% na sub-bacia 3, respectivamente (Tabela 2 e Figura 1).

Tabela 2. Uso do solo das sub-bacias do córrego do Sapo, 2016

\begin{tabular}{lccc}
\hline \multirow{2}{*}{ Uso do solo } & \multicolumn{3}{c}{ Sub-bacias } \\
\cline { 2 - 4 } & $\mathbf{1}$ & $\mathbf{2}$ & $\mathbf{3}$ \\
\cline { 2 - 4 } & \multicolumn{3}{c}{ hectares } \\
\hline Represamento natural & 0,04 & 13 & 46 \\
Vias de acesso & 0,94 & 1,6 & 3,3 \\
Vegetação rasteira & 13,37 & 168 & 980 \\
Vegetação arbórea & 4,25 & 299 & 1.817 \\
Solo exposto & 7,49 & 110 & 221 \\
Infraestrutura & 0,96 & 1,2 & 2,7 \\
Cultivo & 5,25 & 2.054 & 7.743 \\
Urbanização & 0,00 & 1.191 & 2.696 \\
\hline Área total & 32,30 & $3.837,8$ & $13.509,0$ \\
\hline
\end{tabular}




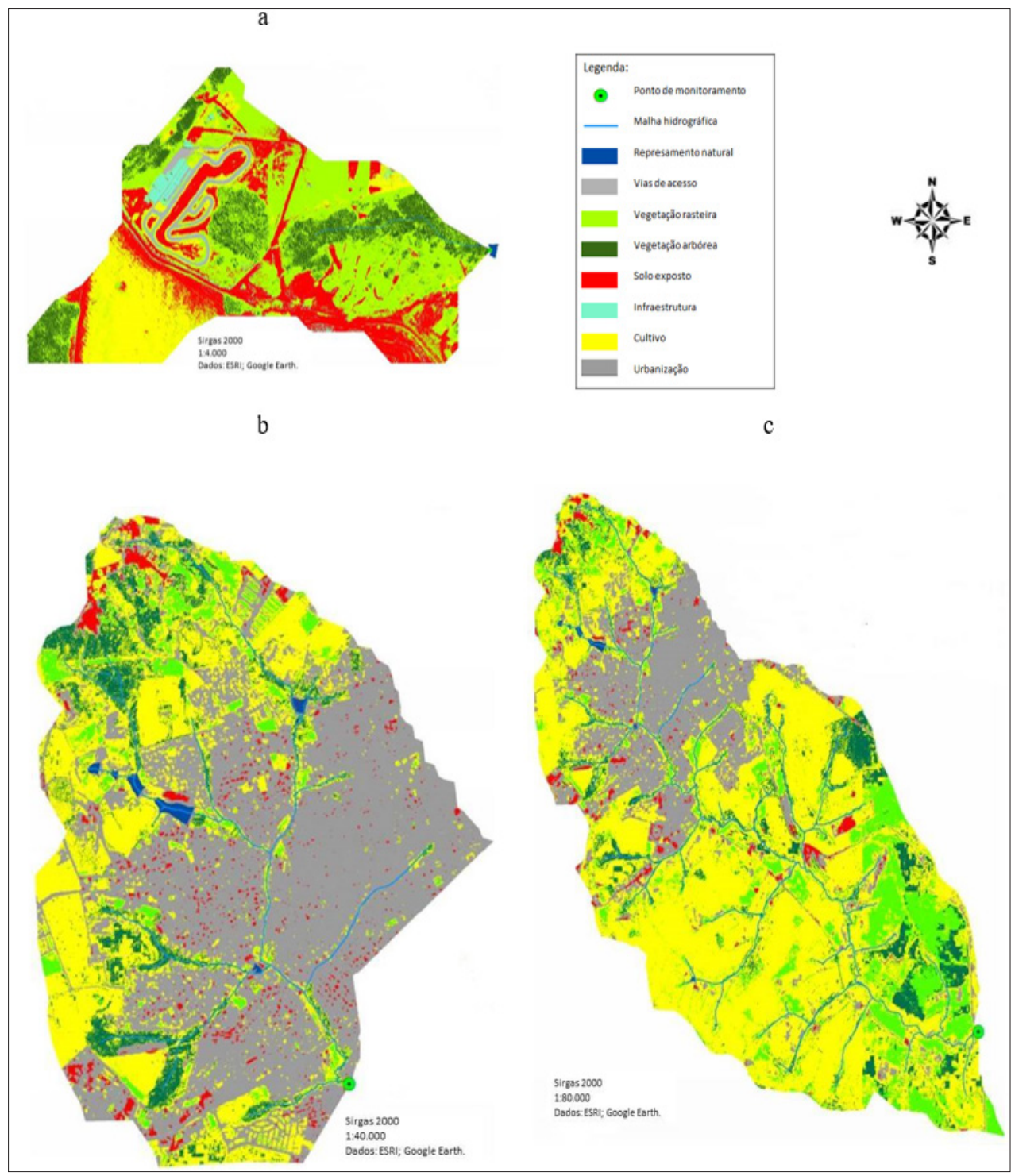

Figura 1. Uso do solo das sub-bacias 1 (a), 2 (b) e 3 (c) do córrego do Sapo, 2016.

Na sub-bacia 1 há predominância de áreas de pastagem com ausência de manejo do solo, porém próximo ao manancial é caracterizado por presença de vegetação arbórea o que assegura parte dos sedimentos conforme já discutido por Vanzela et al. (2010). Resultados semelhantes foram obtidos por Pereira et al. (2016), 
avaliando o uso da terra do rio do Peixe-Boi, Pará, em que constataram que maiores fragmentos de tipologia florestal estão associados às margens dos recursos hídricos.

A montante do ponto analisado há uma pista de motocross e kart e local de retirada de cascalho, evidenciando o segundo maior uso do solo na sub-bacia.

Houve comportamento semelhante de uso do solo nas sub-bacias 2 e 3, com predominância de cultivos, seguido da urbanização. Nota-se que em ambas as sub-bacias reduzidas áreas de preservação permanente (APP) e fragmentos vegetais. A ausência de vegetação ciliar pode comprometer a captação aos usuários da água pela disponibilidade e qualidade conforme já discutido por Vanzela, Hernandez e Franco (2010) e Santos e Hernandez (2013).

Nos últimos sete anos, estima-se que no município de Rio Verde houve um aumento populacional de aproximadamente 21\% (2010/2017, 36 mil habitantes), sendo que o mesmo ocorreu próximo às margens do córrego do Sapo, através de moradias, pontos comerciais e vias de acessos, fazendo com que reduzisse as áreas de preservação permanente e os fragmentos vegetais e consequentemente a qualidade da água do manancial e aumento a quantidade através dos lançamentos clandestinos. Resultados semelhantes foram obtidos por Vanzela, Hernandez e Franco (2010).

A bacia hidrográfica possui várias áreas com solo exposto. Em muitos casos são áreas ociosas para o plantio de milho ou soja. Essas áreas podem comprometer os recursos hídricos por sua proximidade com os mesmos através do carreamento de sedimentos, causando o assoreamento, principalmente no período chuvoso. Para Santos e Hernandez (2013) os represamentos asseguram a maior parte dos sedimentos presentes na água, comprometendo a vida útil dos mesmos. Vanzela et al. (2014), avaliando a produção de sedimentos e do assoreamento em pequena barragem de terra, concluíram que o percentual de retenção de sedimentos é de 53,9 a 94,5\%, o que provocará o assoreamento da represa avaliada $\left(18.598 \mathrm{~m}^{3}\right)$ em no máximo 57 anos.

Resultados semelhantes foram obtidos por Almeida, Bayer e Ferreira Júnior (2016), avaliando sub-bacias com fragilidades naturais e concluíram que as mesmas merecem atenção especial no que diz respeito às atividades de uso e ocupação do solo, as quais, se não forem executadas com cautela poderão potencializar os efeitos dos processos naturais, como a intensificação das perdas de solo por erosão e con- 
sequente assoreamento e diminuição da qualidade da água.

Os resultados das análises física, química e biológica das sub-bacias do córrego do Sapo estão descritos na Tabela 3. Houve degradação da qualidade da água em relação a $\mathrm{pH}$, ferro total, oxigênio dissolvido e coliformes presentes na água.

Tabela 3. Resultados das análises física, química e biológica das sub-bacias do córrego do Sapo, Rio Verde (GO), no ano de 2016

(Continua)

\begin{tabular}{|c|c|c|c|c|}
\hline \multirow{2}{*}{ Parâmetro* } & & \multicolumn{3}{|c|}{ Sub-bacia } \\
\hline & & 1 & 2 & 3 \\
\hline \multirow{2}{*}{$\mathrm{T}$} & Média \pm EPM & $24,3 \pm 2,2$ & $23,7 \pm 1,8$ & $24,0 \pm 1,8$ \\
\hline & Máximo & 26,3 & 26,0 & 25,7 \\
\hline$\left({ }^{\circ} \mathrm{C}\right)$ & Mínimo & 21,0 & 21,0 & 21,0 \\
\hline \multirow{4}{*}{$\begin{array}{c}\mathrm{ST}^{1} \\
\left(\mathrm{mg} \mathrm{L}^{-1}\right)\end{array}$} & Média \pm EPM & $80,9 \pm 44,4$ & $119,1 \pm 38,6$ & $108,8 \pm 26,4$ \\
\hline & Máximo & 116,5 & 172,7 & 115,5 \\
\hline & Mínimo & 43,4 & 76,2 & 73,2 \\
\hline & Não conformidade (\%) & 0,0 & 0,0 & 0,0 \\
\hline \multirow[b]{2}{*}{$\mathrm{TB}^{2}$} & Média \pm EPM & $2,9 \pm 2,6$ & $15,2 \pm 12,1$ & $14,4 \pm 13,0$ \\
\hline & Máximo & 7,4 & 29,3 & 34,6 \\
\hline \multirow{2}{*}{ (NTU) } & Mínimo & 0,6 & 0,4 & 1,0 \\
\hline & Não conformidade (\%) & 0,0 & 0,0 & 0,0 \\
\hline \multirow{4}{*}{$\mathrm{pH}^{3}$} & Média \pm EPM & $6,8 \pm 0,4$ & $7,1 \pm 0,3$ & $7,1 \pm 0,2$ \\
\hline & Máximo & 7,3 & 7,5 & 7,5 \\
\hline & Mínimo & 6,2 & 6,8 & 6,9 \\
\hline & Não conformidade (\%) & 66,7 & 33,3 & 16,7 \\
\hline \multirow[b]{2}{*}{$\mathrm{Ce}^{4}$} & Média \pm EPM & $140,7 \pm 76,1$ & $185,6 \pm 36,5$ & $164,3 \pm 28,9$ \\
\hline & Máximo & 199,0 & 234,0 & 210,0 \\
\hline \multirow{2}{*}{$\left.(\mu \mathrm{S} \mathrm{cm})^{-1}\right)$} & Mínimo & 8,4 & 150,0 & 133,0 \\
\hline & Não conformidade (\%) & 0,0 & 0,0 & 0,0 \\
\hline \multirow{2}{*}{$\mathrm{DT}^{5}$} & Média \pm EPM & $10,4 \pm 10,5$ & $34,3 \pm 11,7$ & $27,4 \pm 13,4$ \\
\hline & Máximo & 23,1 & 49,1 & 39,7 \\
\hline \multirow{2}{*}{$\left(\mathrm{mg} \mathrm{L}^{-1}\right)$} & Mínimo & 1,5 & 22,5 & 11,7 \\
\hline & Não conformidade (\%) & 0,0 & 0,0 & 0,0 \\
\hline \multirow{2}{*}{$\mathrm{Fe}^{6}$} & Média $\pm \mathrm{EPM}$ & $0,3 \pm 0,5$ & $1,1 \pm 1,2$ & $1,5 \pm 1,4$ \\
\hline & Máximo & 1,2 & 2,8 & 3,6 \\
\hline \multirow{2}{*}{$\left(\mathrm{mg} \mathrm{L}^{-1}\right)$} & Mínimo & 0,0 & 0,0 & 0,0 \\
\hline & Não conformidade (\%) & 83,3 & 100,0 & 100,0 \\
\hline
\end{tabular}


(Conclusão)

\begin{tabular}{|c|c|c|c|c|}
\hline \multirow{2}{*}{ Parâmetro* } & & \multicolumn{3}{|c|}{ Sub-bacia } \\
\hline & & 1 & 2 & 3 \\
\hline \multirow{2}{*}{$\mathrm{OD}^{7}$} & Média $\pm E P M$ & $4,9 \pm 0,9$ & $4,6 \pm 0,6$ & $4,8 \pm 0,8$ \\
\hline & Máximo & 6,0 & 5,1 & 5,9 \\
\hline \multirow{2}{*}{$\left(\mathrm{mg} \mathrm{L}^{-1}\right)$} & Mínimo & 3,8 & 3,8 & 3,6 \\
\hline & Não conformidade (\%) & 50,0 & 83,3 & 83,3 \\
\hline \multirow[t]{2}{*}{ DBO } & Média \pm EPM & $2,8 \pm 1,8$ & $5,6 \pm 6,4$ & $6,4 \pm 3,1$ \\
\hline & Máximo & 6,0 & 17,0 & 10,0 \\
\hline$\left(\mathrm{mg} \mathrm{L}^{-1}\right)$ & Mínimo & 2,0 & 2,0 & 3,0 \\
\hline \multirow{2}{*}{ DQO } & Média $\pm \mathrm{EPM}$ & $4,3 \pm 1,0$ & $11,8 \pm 13,5$ & $12,8 \pm 6,9$ \\
\hline & Máximo & 5,0 & 32,0 & 20,0 \\
\hline$\left(\mathrm{mg} \mathrm{L}^{-1}\right)$ & Mínimo & 3,0 & 4,0 & 5,0 \\
\hline \multirow{2}{*}{$\mathrm{N}$} & Média $\pm \mathrm{EPM}$ & $0,13 \pm 0,17$ & $1,33 \pm 1,73$ & $2,60 \pm 4,32$ \\
\hline & Máximo & 0,41 & 4,11 & 10,25 \\
\hline$\left(\mathrm{mg} \mathrm{L}^{-1}\right)$ & Mínimo & 0,03 & 0,26 & 0,16 \\
\hline \multirow[t]{2}{*}{$\mathrm{P}$} & Média \pm EPM & $0,01 \pm 0,01$ & $0,04 \pm 0,05$ & $0,19 \pm 0,22$ \\
\hline & Máximo & 0,02 & 0,11 & 0,53 \\
\hline$\left(\mathrm{mg} \mathrm{L}^{-1}\right)$ & Mínimo & 0,00 & 0,00 & 0,00 \\
\hline \multirow[t]{2}{*}{$\mathrm{K}$} & Média $\pm \mathrm{EPM}$ & $1,61 \pm 1,93$ & $3,34 \pm 2,30$ & $2,20 \pm 1,50$ \\
\hline & Máximo & 4,26 & 5,30 & 3,18 \\
\hline$\left(\mathrm{mg} \mathrm{L}^{-1}\right)$ & Mínimo & 0,01 & 0,01 & 0,01 \\
\hline \multirow{2}{*}{$\mathrm{CT}^{8}$} & Ausente/Presente & Presente & Presente & Presente \\
\hline & Não conformidade (\%) & 50,0 & 100,0 & 100,0 \\
\hline \multirow{2}{*}{$\mathrm{CF}^{9}$} & Ausente/Presente & Presente & Presente & Presente \\
\hline & Não conformidade (\%) & 66,7 & 100,0 & 100,0 \\
\hline
\end{tabular}

"Qualidade da água para fins de irrigação - classe $2 ;{ }^{1}$ Sólidos dissolvidos (baixo $\left(<500 \mathrm{mg} \mathrm{L}^{-1}\right)$, médio (500-2.000 $\left.\mathrm{mg} \mathrm{L}^{-1}\right)$ e alto $\left(>2.000 \mathrm{mg} \mathrm{L}^{-1}\right)$ ) e sólidos suspensos (baixo $\left(<50 \mathrm{mg} \mathrm{L}^{-1}\right)$, médio (50-100 $\left.\mathrm{mg} \mathrm{L} \mathrm{L}^{-1}\right)$ e alto $\left.\left(>100 \mathrm{mg} \mathrm{L}^{-1}\right)\right)$; ${ }^{2}$ adequado $\left(<100 \mathrm{mg} \mathrm{L}^{-1}\right)$ e inadequado $\left(>100 \mathrm{mg} \mathrm{L}^{-1}\right)$; ${ }^{3}$ baixo $(<$ $7,0)$, médio $(7,0-8,0)$ e alto $(>8,0)$; ${ }^{\text {bbaixo }}\left(<250 \mu \mathrm{Scm}^{-1}\right.$ a $\left.25^{\circ} \mathrm{C}\right)$, médio $\left(250-750 \mu \mathrm{S} \mathrm{cm} \mathrm{c}^{-1}\right.$ a $\left.25^{\circ} \mathrm{C}\right) \mathrm{e}$ alto $\left(>750 \mu \mathrm{S} \mathrm{cm}^{-1} \mathrm{a} 25^{\circ} \mathrm{C}\right)$; ${ }^{5}$ Cálcio (normal $\left(\leq 400 \mathrm{mg} \mathrm{L}^{-1}\right)$ e alto $\left(>400 \mathrm{mg} \mathrm{L}^{-1}\right)$ ) e Magnésio (normal ( $\left.\leq 60 \mathrm{mg} \mathrm{L}^{-1}\right)$ e alto $\left.\left(>60 \mathrm{mg} \mathrm{L}^{-1}\right)\right)$; baixo $\left(<0,2 \mathrm{mg} \mathrm{L}^{-1}\right)$, médio $\left(0,2-1,5 \mathrm{mg} \mathrm{L}^{-1}\right)$; e alto $(>1,5$ mg L-1); 'adequado $\left(\geq 5,0 \mathrm{mg} \mathrm{L}^{-1}\right)$ e inadequado $\left(<5,0 \mathrm{mg} \mathrm{L}^{-1}\right) ;{ }^{8}$ adequado $\left(\leq 5.000 \mathrm{NMP} 100 \mathrm{~mL}^{-1}\right)$

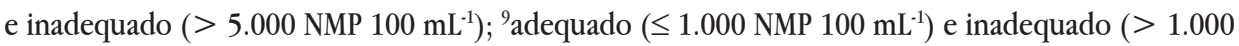
NMP $100 \mathrm{~mL}^{-1}$ ). Fonte dos padrões de cada parâmetro avaliado: Vanzela, Hernandez e Franco (2010). 
Houve moderada redução da temperatura média na sub-bacia 2 e 3 em relação a nascente. Ao contrário do proposto por Menezes et al. (2016), a menor temperatura evidencia que há lançamentos de efluentes líquidos, clandestinos ou não. As menores temperaturas ocorreram no período de estiagem. Lançamentos clandestinos ou não pode haver sedimentos e matéria orgânica de origem fecal, os quais causam entupimento dos sistemas de irrigação e, consequentemente, contaminação dos alimentos se consumidos de forma indireta. Resultados semelhantes foram obtidos por Vanzela, Hernandez e Franco (2010) e Santos e Hernandez (2013) nos seus respectivos pontos de amostragem próximos a áreas urbanas.

Houve baixa concentração de sólidos totais nas três sub-bacias não apresentando sérios riscos de danos aos sistemas de irrigação. As maiores concentrações foram observadas no período de estiagem. Devido a maior demanda por uso dos sistemas de irrigação nessa época, deve-se ter atenção aos acúmulos destes sedimentos ao longo do tempo (dependendo da vazão do sistema) nos finais de linha, sendo necessária a remoção dos sedimentos. As maiores concentrações de sólidos totais foram encontradas na sub-bacia 2 em função do revolvimento do solo em obras de canalização do manancial e construção de vias de acesso em suas proximidades.

A turbidez, a condutividade elétrica e a dureza total não apresentaram riscos de danos aos sistemas de irrigação. Mesmo com valores dentro dos padrões, houve maior concentração média de turbidez na segunda sub-bacia por ausência de áreas de preservação permanente (APP) e erosão urbana.

Os valores de condutividade elétrica foram moderadamente superiores após a área urbana, resultados estes que corroboram com Dalastra et al. (2014) e Oliveira, Nogueira e Sartori (2014) em condições semelhantes. As maiores concentrações desses elementos foram registradas no período chuvoso.

A atenção maior da dureza total se dá pela presença de cálcio e magnésio. Valores acima de $43 \mathrm{mg} \mathrm{L}^{-1}$ podem ocasionar a precipitação de fertilizantes fosfatados e obstrução de orifícios de passagem de água, além de ter efeito laxativo (DALASTRA et al., 2014). Mesmo com a baixa tecnologia empregada nas áreas agrícolas em relação ao manejo do solo, principalmente nas áreas de pastagens, não houve degradação da qualidade da água devido a presença de cálcio e magnésio na mesma. 
Com o pH médio entre 6,0 e 8,0 representa uma leve acidez a alcalino, além de estar associado à entrada de matéria orgânica e efluentes domésticos. Para Dalastra et al. (2014), além das ações antropogênicas, o pH pode ser afetado também pelo $\mathrm{pH}$ do solo. A predominância de $\mathrm{pH}$ ácido pode causar a corrosão dos sistemas de irrigação, reduzindo a eficiência do equipamento e consequentemente de molhamento. Resultados semelhantes foram obtidos por Araújo et al. (2015), avaliando a qualidade da água do córrego Sujo, Teresópolis, Rio de Janeiro.

A região do município de Rio Verde possui solos ricos em ferro e este elemento é o principal causador de danos junto aos sistemas de irrigação. No período seco, período de maior demanda pelo uso da água, todos os pontos monitorados apresentaram médio a alto potencial de danos aos sistemas de irrigação, exceto em uma campanha de campo.

O acúmulo de ferro na água é agravado no período seco devido à redução da vazão, concentrando esse elemento na água devido aos impactos junto ao solo, sendo inversamente no período chuvoso. As áreas de pastagem, má conservação do solo, ausência de APP, e consequentemente má conservação do solo, também influenciaram no aumento da concentração de ferro na água. No período chuvoso, o potencial de danos aos sistemas de irrigação é baixo a médio.

Aos sistemas de irrigação estão sujeitos a incrustação e, consequentemente, entupimento de tubos e aspersores, principalmente em se tratando de sistemas de gotejamento e micro aspersão, onde a suscetibilidade a problemas, principalmente de obstrução de emissores, é maior, afetam o coeficiente de uniformidade de aplicação de água (ZAMBERLAN et al., 2013). Resultados semelhantes foram obtidos por Vanzela, Hernandez e Franco (2010), Santos e Hernandez (2013) e Dalastra et al. (2014).

Os elementos discutidos abaixo (OD, DBO, DQO, N, P, K, CT e CF) não apresentam danos aos sistemas de irrigação e nem trazem prejuízos às culturas, porém se identificadas altas concentrações, representam indícios de contaminação do manancial de origem urbana ou agrícola. Os valores de contaminação das águas mais expressivos foram obtidos no período de estiagem e próximos à área urbana. Resultados semelhantes foram obtidos por Bertossi et al. (2013), avaliando a qualidade de água em microbacias hidrográficas com diferentes coberturas do solo no Sul do Espírito Santo. 
O ganho em qualidade no último ponto de amostragem é devido ao aumento da contribuição de afluentes que não compreende a área urbana e a autodepuração da matéria orgânica ocorre pela grande distância dos pontos de lançamento (área urbana).

Conforme Araújo et al. (2015), o carreamento da matéria orgânica, não necessariamente fecal, pode ter origem na flora e na fauna do entorno. Portanto, estes resultados se assemelham com Menezes et al. (2016), que também obtiveram maiores valores de $\mathrm{DBO}$, consequentemente, de coliformes nos pontos de monitoramento com áreas de influência urbana, que indicam que há lançamentos clandestinos de esgoto e resíduos sólidos urbanos no manancial.

Houve contaminação das águas por coliformes em todos os pontos de amostragem. Na nascente, parte das amostras apresentou ausência de coliformes, principalmente no período chuvoso. Resultados semelhantes foram obtidos por Menezes et al. (2016).

Nas sub-bacias 2 e 3, em todos os pontos de amostragem houve presença de coliformes na água. Embora a coleta de esgoto seja realizada em uma grande percentagem do município de Rio Verde, algumas áreas contam com sistemas sépticos ou ligações clandestinas. Assim, o excesso de coliformes restringe o uso da água, sendo permitido somente para espécies arbóreas, cereais e forrageiras, as quais ocorrem na região estudada, porém, não são irrigadas. A prática da irrigação na área de estudo é de hortaliças. Portanto, o uso dessa água para irrigação, principalmente para alimentos de consumo indireto, é restrito.

Resultados semelhantes foram obtidos por Ternus et al. (2011), Bertossi et al. (2013), Araújo et al. (2015), Carvalho et al. (2015) e Menezes et al. (2016). Assim como Pereira et al. (2016), que avaliaram o uso da terra e degradação na qualidade da água na bacia hidrográfica do Rio do Peixe Boi, Paraíba, Brasil, e concluíram que em todos os pontos amostrais, a qualidade da água foi inversamente proporcional a sua proximidade em relação às áreas antropizadas. Sherer et al. (2016) concluíram que a contaminação de hortaliças por microrganismos patogênicos está diretamente relacionada com a qualidade das águas de irrigação e com o solo onde se encontram.

A distribuição dos pontos foi semelhante para as sub-bacias 2 e 3 e diferentes para a sub-bacia 1, formado dois grupos (Figura 2). A similaridade é representada pelo comportamento da qualidade da água homogêneo entre os dois últimos 
pontos de amostragens e heterogêneo se comparados com o primeiro, conforme já discutido na Tabela 3.

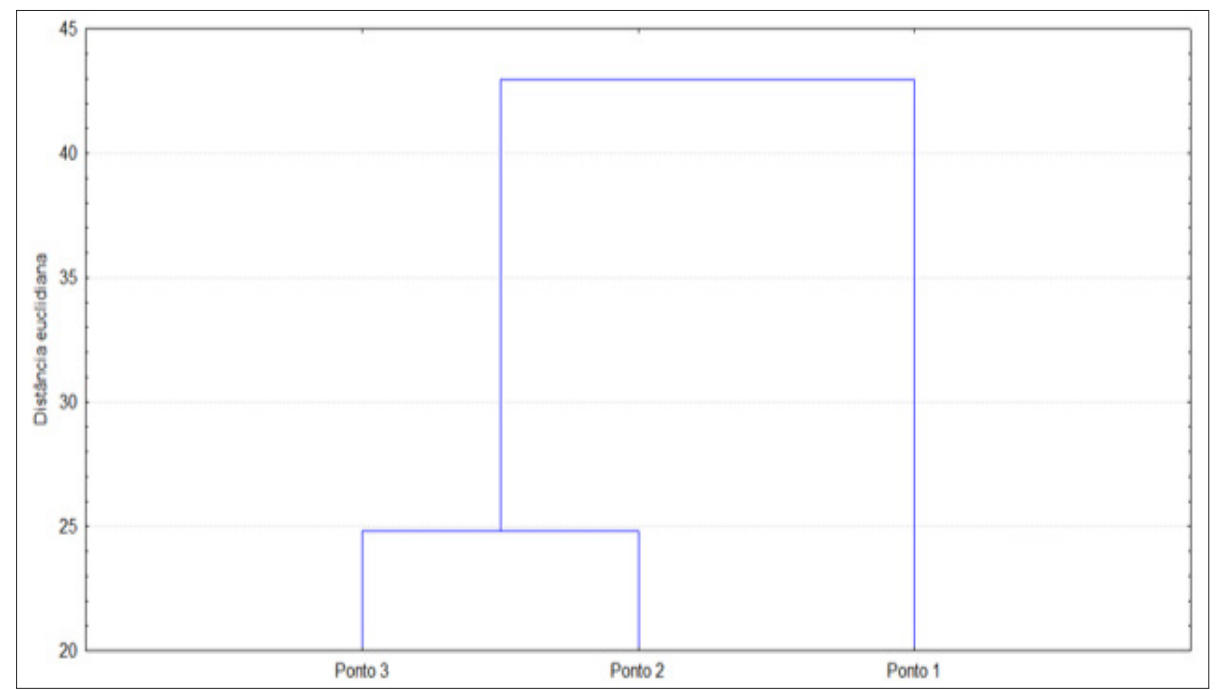

Figura 2. Dendrograma mostrando a semelhança dos pontos de monitoramento para a qualidade de água nas sub-bacias do córrego do Sapo, Rio Verde, Goiás.

Houve relação proporcional e inversa entre os elementos analisados (Figura 3). Com o aumento dos parâmetros físicos na água, há um aumento da carga orgânica. Isso ocorre por que junto aos parâmetros físicos, há cargas orgânicas. $\mathrm{O}$ aumento de ferro é proporcional ao aumento da turbidez. A temperatura, condutividade elétrica e sólidos na água é inversamente proporcional ao oxigênio dissolvido na água. Resultados semelhantes foram obtidos por Menezes et al. (2016) no verão. 


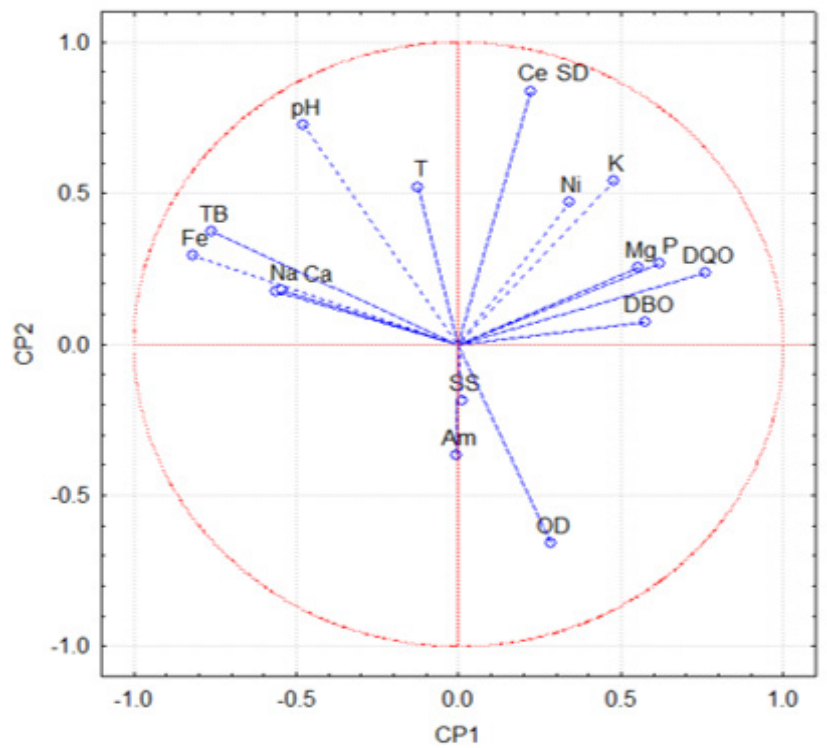

Figura 3. Biplot da qualidade de água da bacia hidrográfica do córrego do Sapo, Rio Verde, Goiás, no ano de 2016.

A água de irrigação tem influência não somente nas culturas irrigadas, mas também no solo onde elas se desenvolvem, podendo modificar sua composição física, química e mesmo microbiológica (ARAÚJO et al., 2015), justificando a importância do monitoramento contínuo nas áreas de influências urbanas.

Portanto, as áreas rurais também merecem atenção especial pela produção de sedimentos orgânicos e inorgânicos ao longo do ano. Para Souza e Gastaldini (2014) as bacias onde predominam áreas agrícolas há aumento da turbidez e sólidos suspensos provocados pelo processo erosivo.

O córrego do Sapo possui índice de qualidade da água (IQA) ótimo (80-100) para a nascente e bom (52-79) para as sub-bacias 2 e 3 , sendo que os valores obtidos nas sub-bacias 1, 2 e 3 foram 82,8, 77,5 e 76,6, respectivamente. De acordo com Zamberlan et al. (2013), valores de IQA entre 70 a 100 se caracterizam como água de boa qualidade e baixo risco para a atividade, podendo ser utilizada em diferentes tipos de solo, clima e cultivos, salvo em determinados casos pontuais, conforme ocorreu neste trabalho.

O índice de estado trófico (IET) da água foi inferior a 47 em todos os pontos 
de monitoramento, classificando a água do manancial como ultraoligotrófico, independente da época do ano e ponto de coleta.

Mesmo com bons índices de qualidade da água (IQA e IET) deve haver monitoramento constante da qualidade da água do córrego do Sapo, pois, houve parâmetros que restringem o uso da água, dependendo da finalidade.

A bacia hidrográfica do córrego do Sapo gera em média $69,3 \mathrm{~m}^{3} \mathrm{~h}^{-1}$ por $\mathrm{km}^{2}$ de área. Houve boa disponibilidade hídrica em todos os pontos de monitoramento (Tabela 4), sendo que muitas das vezes os mananciais que compreendem as sub-bacias são negligenciados, podendo esses se tornar fonte de renda através da agricultura irrigada. Resultados semelhantes foram obtidos por Vanzela, Hernandez e Franco (2010) e Santos e Hernandez (2013).

Tabela 4. Disponibilidade hídrica das sub-bacias do córrego do Sapo, Rio Verde (GO), no ano de 2016

\begin{tabular}{cccc}
\hline \multirow{2}{*}{ Disponibilidade hídrica $\left(\mathrm{m}^{3} \mathrm{~h}^{-1}\right)$} & \multicolumn{3}{c}{ Sub-bacias } \\
\cline { 2 - 4 } & 19,2 & 5.568 & 20.852 \\
Máximo & 5,8 & 1.145 & 2.492 \\
Mínimo & $10,6 \pm 5,2$ & $3.518 \pm 1.966$ & $9.545 \pm 7.349$ \\
Média & 4,9 & 626,2 & $2.247,2$ \\
\hline Vazão de referência $\left(\mathrm{Q}_{95 \%}\right)$ & 2,5 & 313,1 & $1.123,6$ \\
\hline Vazão outorgável $\left(50 \%\right.$ da $\left.\mathrm{Q}_{95 \%}\right)$ & & & \\
\hline
\end{tabular}

Houve aumento médio de vazão do ponto 1 ao 2 de 331 vezes superior e do ponto 2 ao 3 de 2,7 vezes superior. Esse elevado aumento da vazão no segundo ponto é devido à influência de 17 nascentes e a área urbana ao longo do percurso, além da área de contribuição. $O$ último ponto possui influência de mais 7 nascentes.

A maior variação da vazão foi encontrada nos pontos de maior disponibilidade. Esse fato ocorre devido ao desequilíbrio aos corpos hídricos provocados pela urbanização no seu entorno. A ausência de mata ciliar pode ser observada durante as coletas, trazendo interferências na sua vazão. Segundo Menezes et al. (2016), a variação da vazão reflete diretamente na qualidade da água na diluição dos poluentes.

Mesmo com um longo período de estiagem (6 meses), o córrego do Sapo possui potencial de irrigar nas sub-bacias 1, 2 e 3, em qualquer época do ano, uma 
área de aproximadamente 2, 250 ou 899 hectares, respectivamente, considerando a evapotranspiração potencial média de $3 \mathrm{~mm} \mathrm{dia}^{-1}$. Mesmo no período de estiagem, a vazão de referência foi superior a vazão mínima.

O córrego do Sapo possui boa localização estratégica por compreender a área urbana, inclusive, margear a atual área de lazer do município popularmente conhecida como "Espelho d'água", além de apresentar potencial para uso na agricultura irrigada. Devido ao excesso de contaminação e degradação do córrego do Sapo, o manancial está impedido de uso para as práticas esportivas de contato primário, assim como para uso de irrigação de hortaliças e frutíferas, o que pode vir a comprometer a economia local. Portanto, este estudo demonstra a urgência de implementar medidas para conservação dos ecossistemas aquáticos e seu entorno.

\section{CONSIDERAÇÕES FINAIS}

A bacia hidrográfica do córrego do Sapo se caracterizou com maior parte agrícola (57,3\%), portanto, os impactos de restrição de uso da água são advindos em maior parte da área urbana (20\%).

Houve bons índices de qualidade da água e potencial de irrigar até 899 hectares, portanto, as expansões das áreas urbanas e o uso do solo na área rural sem planejamento podem comprometer esse índice devido aos lançamentos clandestinos, vindo a comprometer a qualidade da água.

Devido à presença de ferro na água, a instalação de sistemas de irrigação deve ser acompanhada de sistemas de filtragem para retenção das partículas e, consequentemente, melhor aproveitamento do equipamento.

As reduções da qualidade da água ocorrerão nas estações do ano que registraram as menores disponibilidades hídricas (outono-inverno). A disponibilidade hídrica passa por oscilações devido à falta de áreas de preservação permanente, tanto na área urbana quanto rural, podendo assim influenciar também na quantidade de poluentes na água.

Há necessidade de implementar medidas de planejamento estratégico de gestão dos recursos hídricos na bacia hidrográfica do córrego do Sapo para recuperação e melhoria da qualidade da água. 


\section{AGRADECIMENTOS}

Os autores agradecem à Universidade de Rio Verde (UniRV) pela concessão da bolsa de pesquisa na chamada interna 01/2016 - PRPPG/UniRV ( ${ }^{\circ} 018.2016 .3 .06$ ) e ao Engenheiro Ambiental Fernando Santiago do Prado pela confecção dos mapas.

\section{REFERÊNCIAS}

ACQUA, N. H. D.; SILVA, G. P.; BENITES, V. M.; ASSIS, R. L.; SIMON, G. A. Métodos de amostragem de solos em áreas sob plantio direto no sudoeste goiano. Revista Brasileira de Engenharia Agrícola e Ambiental, Campina Grande, v. 17, n. 2, p. 117-122, nov./2012. 2013.

ALMEIDA, R. F. B.; BAYER, M.; FERREIRA JÚNIOR, L. G. Compartimentação morfométrica da bacia do rio Coco como subsídio a análise de fragilidade ambiental. Mercator, Fortaleza, v. 15, n. 4, p. 83-94, out./dez. 2016.

ARAÚJO, F. V.; VIEIRA, L.; JAYME, M. M. A.; NUNES, M. C. N.; CORTÊS, M. Avaliação da qualidade da água utilizada para irrigação na bacia do Córrego Sujo, Teresópolis, RJ. Caderno Saúde Coletiva, Rio de Janeiro, v. 23, n. 4, p. 380-385, out./dez. 2015.

BERTOSSI, A. P. A.; CECÍLIO, R. A.; NEVES, M. A.; GARCIA, G. O. Qualidade da água em microbacias hidrográficas com diferentes coberturas do solo no sul do Espírito Santo. Revista Árvore, Viçosa, v. 37, n. 1, p. 107-117, jan./mar., 2013.

BRASIL. Instituto Brasileiro de Geografia e Estatística. Censo demográfico 2010. Brasília: Ministério do Planejamento e Orçamento, 2010.

CARVALHO, K. Q.; LIMA, S. B.; PASSIG, F. H.; GUSMÃO, L. K.; SOUZA, D. C.; KREUTZ, C.; BELINI, A. D.; ARANTES, E. J. Influence of urban area on the water quality of the Campo River basin, Paraná State, Brazil. Brazilian Journal Biology, São Carlos, v. 75, n. 4, supplement 2, p. 96-106, mai. 2015.

DALASTRA, C.; HERNANDEZ, F. B. T.; BARBOZA, G. C.; SONEGO, C. R. Qualidade 
da água do córrego do Cedro para fins de irrigação na produção de alimentos in-natura. Revista de Agricultura Neotropical, Cassilândia, v. 1, n. 2, p. 52-63, out./ dez. 2014.

INSTITUTO MINEIRO DE GESTÃO DAS ÁGUAS - IGAM. Sistema de cálculo da qualidade da água (SCQA): estabelecimento das equações do Índice de Qualidade das Águas (IQA). Relatório 1. 2005. Disponível em: < http://aguas.iguam.mg.gov.br/ aguas/downloads/SCQA_final.pdf>. Acesso em: 05 dez. 2016.

INSTITUTO NACIONAL DE METEOROLOGIA (INMET). Dados climáticos da Estação de Rio Verde: série histórica de 1961 a 2015. Banco de dados do Instituto Nacional de Meteorologia. 2015.

LAMPARELLI, M. C. Graus de trofia em corpos de água do estado de São Paulo: avaliação dos métodos de monitoramento. 207f. Tese (Doutorado em Ecossistemas Terrestres e Aquáticos) - Instituto de Biociências, Universidade de São Paulo, 2004.

MENEZES, J. P. C.; BITTENCOURT, R. P.; FARIAS, M. S.; BELLO, I. P.; FIA, R.; OLIVEIRA, L. F. C. Relação entre padrões de uso e ocupação do solo e qualidade da água em uma bacia hidrográfica urbana. Revista Engenharia Sanitária \& Ambiental, Rio de Janeiro, v. 21, n. 3, p. 519-534, jul./set. 2016.

OLIVEIRA, P. C. R.; NOGUEIRA, M. G.; SARTORI, L. P. Differential environmental impacts on small and médium size rivers from center os São Paulo State, Brazil, and regional mangement perspectives. Acta Limnologica Brasiliensia, Rio Claro, v. 26, n. 4, p. 404-419, out./dec. 2014.

PEREIRA, B. W. F.; MACIEL, M. N. M.; OLIVEIRA, F. A.; ALVES, M. A. M. S.; RIBEIRO, A. M.; FERREIRA, B. M.; RIBEIRO, E. G. P. Uso da terra e degradação na qualidade da água na bacia hidrográfica do rio Peixe-Boi, PA, Brasil. Revista Ambiente \& Água, Taubaté, v. 11, n. 2, p. 472-485, abr./jun. 2016.

PRADO, F. S.; SANTOS, G. O.; FERREIRA, H. A.; ARANTES, J. O.; SIEBA, W. R. Cobertura vegetal em áreas verdes urbanas no município de Rio Verde, Goiás. In: CONGRESSO DE INICIAÇÃO CIENTÍFICA DA UNIVERSIDADE DE RIO VERDE, XI, 2017, Rio Verde, Goiás. Anais... Rio Verde: UniRV, 2017, p. 267-270. 
SANTOS, G. O.; HERNANDEZ, F. B. T. H. Uso do solo e monitoramento dos recursos hídricos no córrego do Ipê, Ilha Solteira, SP. Revista Brasileira de Engenharia Agrícola e Ambiental, Campina Grande, v. 17, n. 1, p. 60-68, jan. 2013.

SCHERER, K.; GRANADA, C. E.; STÜLP, S.; SPEROTTO, R. A. Avaliação bacteriológica e físico-química de águas de irrigação, solo e alface (Lactuca sativa L.). Revista Ambiente \& Água, Taubaté, v. 11, n. 3, p. 665-675, jul./set. 2016.

SOUZA, M. M.; GASTALDINI, M. C. C. Avaliação da qualidade da água em bacias hidrográficas com diferentes impactos antrópicos. Revista Engenharia Sanitária e Ambiental, Rio de Janeiro, v. 19, n. 3, p. 263-274, jul./set. 2014.

RIO VERDE, PREFEITURA MUNICPIAL DE. Infraestrutura. Disponível em: < http:// www.rioverdegoias.com.br/i.php?si=aci\&id=4>. Acesso em: 05 dez. 2016.

TERNUS, R. Z.; SOUZA-FRANCO, G. M.; ANSELMINI, M. E. K.; MOCELLIN, D. J. C.; MAGRO, J. D. Influence of urbanisation on water quality in the basin of the upper Uruguay River in western Santa Catarina, Brazil. Acta Limnologica Brasiliensia, Rio Claro, v. 23, n. 2, p. 189-199, abr./jun. 2011.

VANZELA, L. S.; GRECCO, D. L. G.; COSTA NETO, J. N.; SANTOS, G. O. Evaluation of sediment production and siltation in a small Earth dam in Fernandópolis, SP. Engenharia Agrícola, Jaboticabal, v. 34, n. 5, p. 912-924, set./out. 2014.

VANZELA, L. S.; HERNANDEZ, F. B. T.; FRANCO, R. A. M. Influência do uso e ocupação do solo nos recursos hídricos do Córrego Três Barras, Marinópolis. Revista Brasileira de Engenharia Agrícola e Ambiental, Campina Grande, v. 14, n. 1, p. 55-64, jan. 2010.

ZAMBERLAN, J. F.; ROBAINA, A. D.; PEITER, M. X.; FERRAZ, R. C.; PINTO, L. M. Índices sazonais de qualidade da água de irrigação via análise multivariada na região central do Rio Grande do Sul. Irriga, Botucatu, v. 18, n. 3, p. 376-386, jul./set., 2013. 